\title{
Prediction of In-situ CBR of Subgrade Cohesive Soils from Dynamic Cone Penetrometer and Soil Properties
}

\author{
M. M. E. Zumrawi
}

\begin{abstract}
The aim of this paper is to predict the field CBR of different types of soils. Since CBR can't be easily measured in the field, prediction of CBR from other simple tests such as Dynamic Cone Penetrometer (DCP) and soil properties is a valuable alternative. Various soils have been compacted at different initial state conditions (i.e. water content and dry density) then using laboratory and field equipment to enable the measurement of unsoaked CBR and DCP of these soils. Analysis of the experimental data indicated that there is a very good linear relationship of the measured soil strength (i.e. unsoaked CBR and DCP) with the soil initial state factor as described by the combination of initial dry density, water content and void ratio. Comparison of the measured and predicted values of unsoaked CBR and DCP using the developed equation clearly indicates the validity of this equation.
\end{abstract}

Index Terms-Dynamic cone Penetrometer (DCP), in-situ CBR and the soil initial state factor.

\section{INTRODUCTION}

The CBR test is the most widespread method of determining the bearing strength of the pavement materials and is fundamental to pavement design practice in most countries. The CBR test can be performed both in the laboratory and field. It is essential that the standard test procedure should be strictly followed [1], [2]. The CBR test may be conducted on remolded or undisturbed soil samples or on the soil in place. The samples may be tested at their natural or as molded water content (unsoaked CBR), or they may be soaked by immersing in water for four days in order to simulate highly unfavorable moisture conditions of the soil type. The CBR may be considered as the strength of the soil relative to that of crushed stone.

The Dynamic Cone Penetrometer (DCP) has been successfully utilized for estimating the strength of soils. The DCP was studied mainly in relation to application in pavement structures and was primarily correlated with California Bearing Ratio (CBR). Since in-situ CBR testing is expensive, relatively slow to conduct, and generally not favoured by highway engineers, DCP, being light and portable, offers an attractive means for determining in-situ CBR at a comparative speed and ease of operation.

The DCP is now being used extensively in South Africa, United Kingdom, United States, Australia, and other countries because it is simple, economical, and able to provide a rapid in-situ of strength and more indirectly

Manuscript received January 9, 2014; revised March 3, 2014.

M. M. E. Zumrawi is with University of Khartoum, Sudan (e-mail: ceuk@sudanet.net). modulus of subgrade as well as pavement structures. In Australia in 1956, Scala [3] developed a portable DCP to evaluate the strength of pavement materials. The Scala penetrometer was subsequently modified by Harison [4]. The DCP used in this investigation consists of a steel rod, $16 \mathrm{~mm}$ diameter, to which a cone with a $20 \mathrm{~mm}$ base diameter and a $60^{\circ}$ cone angle is attached. The DCP is driven into the soil by an $8 \mathrm{~kg}$ drop hammer sliding on a steel rod, with a fall height of $575 \mathrm{~mm}$. Fig. 1 gives a schematic diagram of the DCP test on CBR sample. The DCP is used for measuring the material resistance to penetration in terms of millimeters per blow while the cone of the device is being driven into the soil.

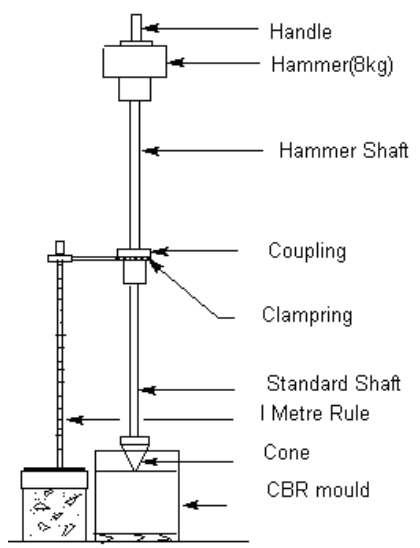

Fig. 1. Arrangement for conducting DCP test on CBR mould [5].

Several correlations have been reported between the DCP and CBR. Livneh [6] compared 21 correlations that were published in the world technical literature. However, many researchers have already pointed out the importance local soil characteristics on the obtained correlation between DCP and CBR. It was reported that differences in geographic areas throughout the world lead to changes in the empirical values obtained [6].

\section{PREVIOUS CORRELATIONS}

To assess the structural properties of the pavement subgrade, the DCP values are usually correlated with the CBR value [6], [7]. Different correlations were suggested between the DCP in ( $\mathrm{mm} / \mathrm{blow})$ and CBR values. DCP tests were conducted on 2,000 samples of pavement materials in standard moulds directly following CBR determination [7]. Based on his results the following correlation was recommended:

$$
\log C B R=2.62-1.27 \log (D C P)
$$

Based on a field study, the following correlation was 
suggested [8]:

$$
\log C B R=2.56-1.15 \log (D C P)
$$

The correlation between the DCP and the in-situ CBR values using a wide range of undisturbed and compacted fine-grained soil samples, with and without saturation was established [9].

$$
\log C B R=2.2-0.71 \log (D C P) 1.5
$$

Eq. (4) was suggested for clayey-like soil of DCP > 10 $(\mathrm{mm} / \mathrm{blow})$ and Eq. 5 for granular soil of DCP $<10(\mathrm{~mm} / \mathrm{blow})$ [10]:

$$
\begin{aligned}
& \log C B R=2.56-1.16 \log (D C P) \\
& \log C B R=2.70-1.12 \log (D C P)
\end{aligned}
$$

For a wide range of granular and cohesive materials, the U.S. Army Corps of Engineers found the relation described in Eq. (6), [11]; this equation was also adopted by many researchers, [12].

$$
\log C B R=2.465-1.12 \log (D C P)
$$

The in-situ CBR was determined using the DCP and material parameters such as grading modulus (GM), plastic limit (PL) and dry density (DD), [13].

$$
\begin{aligned}
\operatorname{Ln} C B R=1.1 & \operatorname{Ln} D C P+0.85(G M) \\
& -0.031(P L)-.001(D D)+7.4
\end{aligned}
$$

TABLE I: THE INDEX PROPERTIES OF THE SOILS STUDIED

\begin{tabular}{|c|c|c|c|c|}
\hline Soil & $\mathrm{G}_{\mathrm{s}}$ & LL $(\%)$ & PI $(\%)$ & $\mathrm{C}(\%)$ \\
\hline A & 2.74 & 41 & 18 & 30 \\
\hline B & 2.72 & 51 & 26 & 50 \\
C & 2.75 & 85 & 58 & 60 \\
\hline
\end{tabular}

\section{EXPERIMENTAL WORK}

The objective of this study is to establish a relationship between field CBR, DCP and soil properties for different types of soils. Three soils of different properties were used as given in Table I. The samples were prepared with different water contents and compacted into a standard CBR mould to different dry densities. To relate CBR and DCP results at the same water content and density a pair of identical samples were prepared. The first was subjected directly to the CBR penetration test as unsoaked CBR and the second was used for DCP test.

The DCP tests were carried out on the surface of the samples confined by the conventional CBR mould under the same surcharge load used in CBR tests. The DCP was directly placed at the surface in the center of the sample. The DCP test was started by sliding the hammer and counting the number of blows to drive the DCP $50 \mathrm{~mm}$ into the sample and taken as the reading of DCP.

The tests results are summarized and presented as given in Table II. These results were analyzed and used to verify the linear relationship between the soil initial state factor and the measured strength parameters, CBR and DCP.

TABLE II: THE TESTS RESUltS OF COMPACTED SOILS SAMPLES

\begin{tabular}{|c|c|c|c|c|c|c|}
\hline Sample & $\begin{array}{c}w \\
\%\end{array}$ & $\begin{array}{c}\rho_{d} \\
\mathrm{~g} / \mathrm{cm}^{3}\end{array}$ & $\mathrm{e}$ & $\mathrm{F}_{\mathrm{i}}$ & $\begin{array}{c}\mathrm{CBR} \\
\%\end{array}$ & $\begin{array}{c}\text { DCP } \\
\mathrm{mm} / \mathrm{blow}\end{array}$ \\
\hline $\mathrm{A}_{1}$ & 14 & 1.389 & 0.97 & 10.2 & 17.1 & 7.8 \\
\hline $\mathrm{A}_{2}$ & 16 & 1.412 & 0.94 & 9.4 & 15.3 & 9.6 \\
\hline $\mathrm{A}_{3}$ & 18 & 1.482 & 0.85 & 9.7 & 14.9 & 11.9 \\
\hline $\mathrm{A}_{4}$ & 20 & 1.578 & 0.74 & 10.7 & 17.4 & 9.5 \\
\hline $\mathrm{A}_{5}$ & 27 & 1.432 & 0.91 & 5.8 & 2.4 & 24.1 \\
\hline $\mathrm{A}_{6}$ & 30 & 1.374 & 0.99 & 4.6 & 1.1 & 27.1 \\
\hline $\mathrm{B}_{1}$ & 17 & 1.344 & 1.02 & 7.7 & 5.2 & 8.5 \\
\hline $\mathrm{B}_{2}$ & 21 & 1.456 & 0.87 & 8.0 & 4.3 & 9.6 \\
\hline $\mathrm{B}_{3}$ & 25 & 1.509 & 0.80 & 7.5 & 4.5 & 10.9 \\
\hline $\mathrm{B}_{4}$ & 37 & 1.355 & 1.01 & 3.6 & 1.0 & 21.5 \\
\hline $\mathrm{B}_{5}$ & 40 & 1.348 & 1.02 & 3.3 & 0.5 & 26.1 \\
\hline $\mathrm{C}_{1}$ & 16.7 & 1.410 & 0.95 & 8.9 & 27.0 & 6.0 \\
\hline $\mathrm{C}_{2}$ & 20.5 & 1.470 & 0.87 & 8.2 & 21.6 & 6.8 \\
\hline $\mathrm{C}_{3}$ & 23.7 & 1.510 & 0.82 & 7.8 & 20.0 & 7.7 \\
\hline $\mathrm{C}_{4}$ & 27.6 & 1.460 & 0.88 & 6.0 & 6.9 & 10.0 \\
\hline $\mathrm{C}_{5}$ & 29.1 & 1.430 & 0.92 & 5.3 & 2.9 & 16.0 \\
\hline $\mathrm{C}_{6}$ & 32.6 & 1.390 & 0.98 & 4.4 & 1.6 & 22.0 \\
\hline $\mathrm{C}_{7}$ & 40.0 & 1.391 & 0.98 & 3.6 & 1.0 & 29.0 \\
\hline & & & & & & \\
\hline
\end{tabular}

TABLE III: SUMMARY OF REGRESSION ANALYSIS RESULTS

\begin{tabular}{|c|c|c|c|c|}
\hline Measured Data & Soil & $\mathrm{F}_{0}$ & $\mathrm{M}$ & $\mathrm{R}^{2}$ \\
\hline \multirow{3}{*}{ CBR } & $\mathrm{A}$ & 4.22 & 2.45 & 0.81 \\
\cline { 2 - 5 } & $\mathrm{B}$ & 2.59 & 0.83 & 0.91 \\
& $\mathrm{C}$ & 4.16 & 5.04 & 0.85 \\
\hline \multirow{2}{*}{$\mathrm{DCP}$} & $\mathrm{A}$ & 13.05 & -3.23 & 0.96 \\
\hline \multirow{3}{*}{$\mathrm{CBR} / \mathrm{DCP}$} & $\mathrm{B}$ & 10.62 & -3.33 & 0.97 \\
& $\mathrm{C}$ & 9.13 & -4.72 & 0.97 \\
\hline & $\mathrm{A}$ & 4.95 & 3.38 & 0.91 \\
\hline & $\mathrm{B}$ & 3.16 & 1.07 & 0.92 \\
& $\mathrm{C}$ & 4.39 & 8.41 & 0.90 \\
\hline
\end{tabular}

\section{ANALYSIS AND RESULTS}

The use of DCP test and soil properties to predict the field CBR is preferred because it is simple and inexpensive and it enables rapid measurements of the in-situ strength of pavement layers and subgrades. Several correlations developed between the DCP penetration rates and CBR values are available in the literature. This paper aims to develop correlations between in-situ CBR, DCP and soil properties as described by a new concept, factor of soil initial state parameters. This factor was developed from easy measured soil index properties such as water content, dry density, void ratio, plasticity index and clay content.

\section{A. The Initial State Factor}

The initial state factor of compacted soil was first developed by Mohamed [14] and then modified by Zumrawi [15]. The initial state factor $\left(F_{i}\right)$ is defined as a combination of the soil initial state parameters such as dry density $\left(\rho_{d}\right)$, water content $(\omega)$ and void ratio $(e)$ and can be expressed thus:

$$
F_{i}=\frac{\rho_{d}}{\rho_{\omega}} \cdot \frac{1}{\omega \cdot e}
$$

where: $\rho_{\omega}$ is the water density, the void ratio $(e)$ can be calculated using the following equation:

$$
e=\frac{G_{s}}{\rho_{d}}-1
$$


where: $G_{s}$ is the specific gravity of soil.

\section{B. The Initial State Factor and Strength Relationship}

To investigate the relationship between the initial state factor, $\mathrm{F}_{\mathrm{i}}$ and the soil strength measured by CBR and DCP, the tests results obtained in this study were analysed. The CBR tests results and the data analysis as given in Table I were drawn in Fig. 2. The plots in this figure clearly indicate that a linear relationship exists between the initial state factor, $\mathrm{F}_{\mathrm{i}}$ and the CBR. Hence, the initial state factor, $F_{i}$ can be assumed to be directly proportional to the CBR i.e.

$$
F_{i} \propto C B R
$$

The experimental results and the data analysis of DCP as given in Table I and indicated in Fig. 3 suggest that an inverse linear relationship exists between the DCP and the initial state factor, $F_{i}$. Hence, it can be assumed that the DCP is inversely proportional to the initial state factor, $F_{i}$ i.e.

$$
F_{i} \propto \frac{1}{D C P}
$$

From the above Eq. (10) and (11) it can be concluded that the initial state factor, $F_{i}$ is directly proportional to the ratio of CBR to DCP. This relationship can be expressed as:

$$
F_{i} \propto \frac{C B R}{D C P}
$$

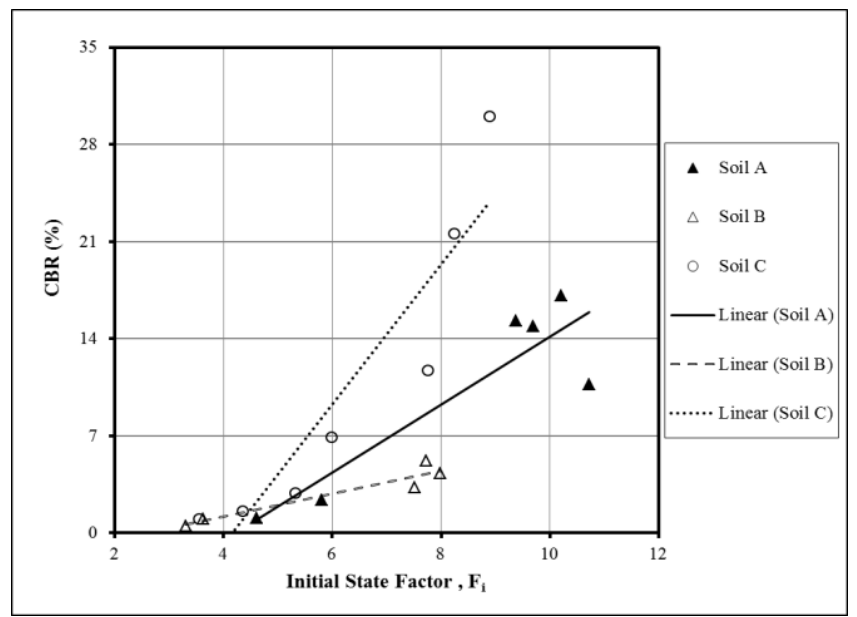

Fig. 2. The linear relationship between CBR and Initial state factor, $F_{i}$ for the tested soils.

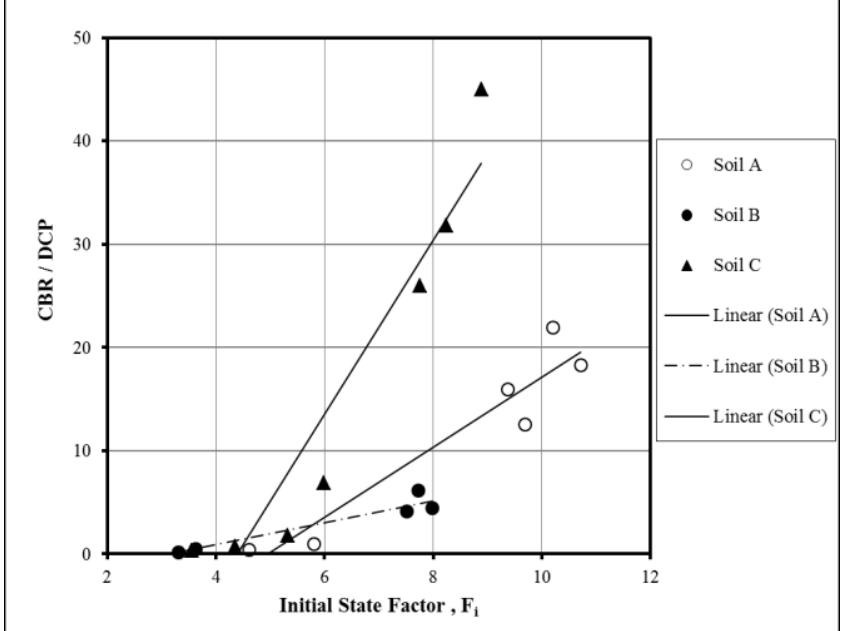

Fig. 4. The Linear Relationship between the ratio of CBR / DCP and Initial state factor, $\mathrm{Fi}$ for the tested soils.
Relationship between the initial state Factor, $F i$ and the ratio of CBR to DCP for the three soils tested were shown in Fig. 4. The plots in this figure and the value of the correlation coefficient (R2), as given in Table III have clearly indicated that a direct linear relationship exists between the initial state factor and the ratio of CBR to DCP for all the data analysed. Thus, the straight line shown in the plots of Fig. 4 can be expressed as:

$$
C B R / D C P=M *\left(F_{i}-F_{0}\right)
$$

where: $F_{0}$ is the value of $F_{i}$ at zero CBR/DCP, $M$ is the gradient of the straight line.

For the data of CBR / DCP, the relationship of $F_{0}$ and $M$, as given in Table III with plasticity index and clay content was plotted in Fig. 5. The equations of the best fit are expressed thus:

$$
\begin{gathered}
F_{0}=0.027(P I * C)^{-2}-0.541(P I * C)^{-1}+5.72 \\
M=26.51 \log (P I * C)+8.89
\end{gathered}
$$

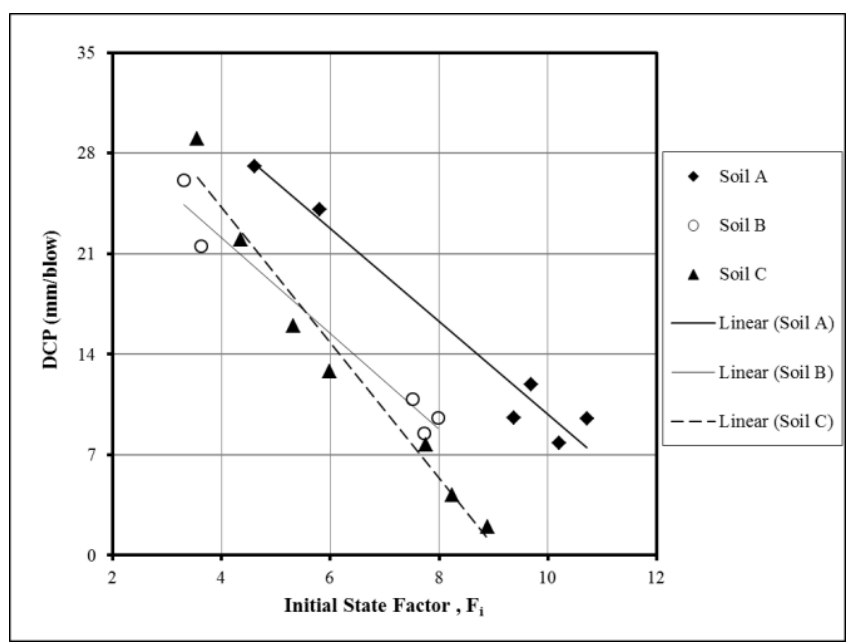

Fig. 3. The linear relationship between DCP and initial state factor, $F_{i}$ for the tested Soils.

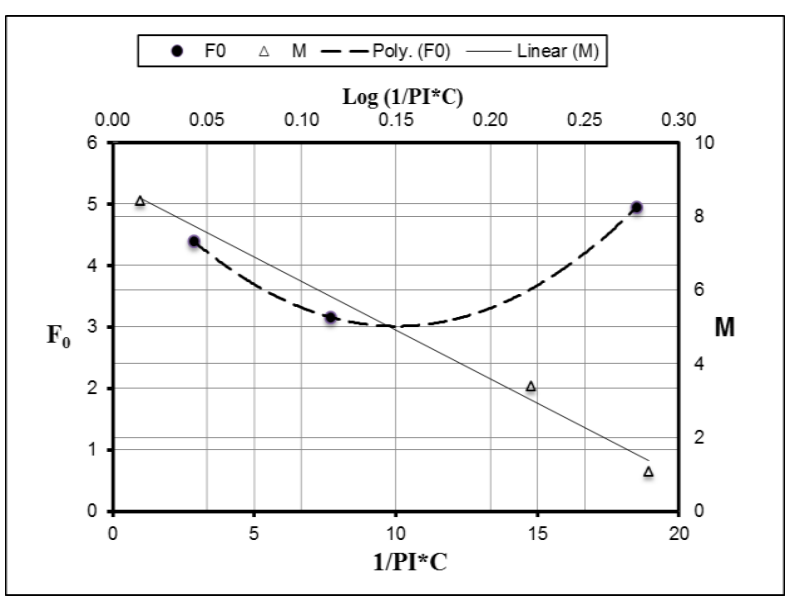

Fig. 5. Variation of $F_{0}$ and $\mathrm{M}$ with plasticity index and clay content for the ratio CBR / DCP data.

By substituting the above Eq. (14) and (15) in the general experiment Eq. (13) and rearranged to express CBR as:

$$
\begin{aligned}
\frac{C B R}{D C P}= & {\left[26.51 \log \left(P I^{*} C\right)+8.89\right] } \\
& {\left[F_{i}-0.0269 *(P I * C)^{-2}+0.541\left(P I^{*} C\right)^{-1}-5.72\right] }
\end{aligned}
$$




$$
\begin{aligned}
& C B R=(D C P) {\left[\log \left(P I^{*} C\right)^{26.51}+8.89\right] } \\
& {\left[F_{i}-\frac{0.0269}{(P I * C)^{2}}+\frac{0.541}{P I * C}-5.72\right] }
\end{aligned}
$$

where: $F_{i}:$ is the initial state factor, $D C P$ is the dynamic cone penetration (mm/blow), $P I$ : is the plasticity index, $C$ : is the clay content.

To check the validity of the proposed correlation, the ratio CBR / DCP values obtained from the proposed Eq. (16) are compared with the measured CBR / DCP values as given in Fig. 6. As can be seen from the points are found to fall close to the line of equality indicating good prediction. Therefore by using Eq. (17), the DCP can be used to predict the in-situ CBR value for the different pavement layers and subgrades to the depth of penetration.

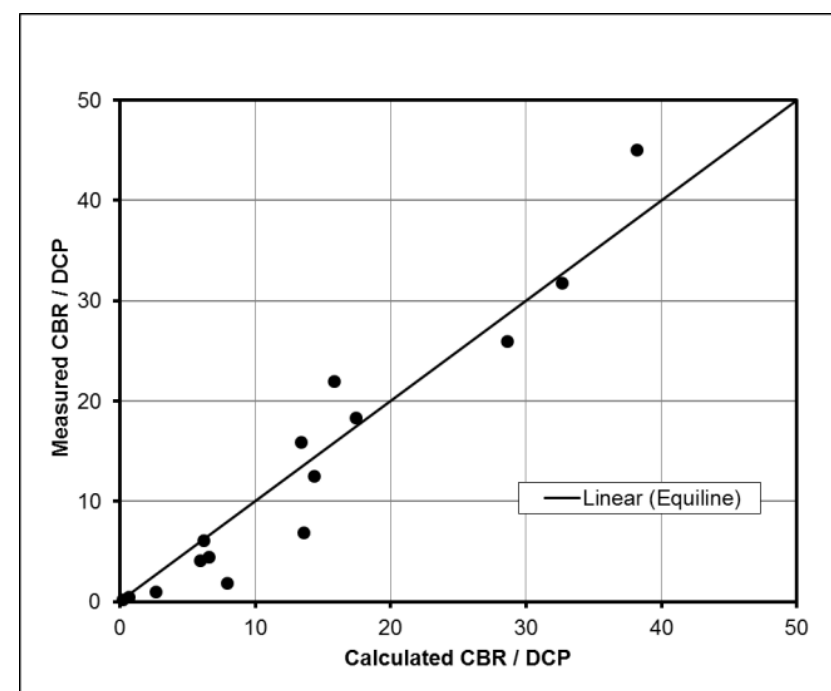

Fig. 6. Comparison of measured / predicted CBR / DCP for tests results.

\section{CONCLUSIONS}

This study showed that the DCP is the most simple and inexpensive test and is preferred to predict the in-situ CBR for the different pavement layers. Several correlations were developed between the DCP with the CBR. The proposed relation was developed from easy measured soil index properties.

Analysis of the experimental results demonstrates very clearly that a direct linear relationship exists between the initial state Factor, $\mathrm{F}_{\mathrm{i}}$ and the soil strength measured by CBR and DCP. The coefficients of this linear relationship (i.e. constant and slope) were found to depend on plasticity index and clay content of soil.

The results of this study indicated that the soil initial state factor can reliably predict the strength measured by CBR and DCP, and thus can be used to evaluate the strength characteristics of compacted soils, subgrade, base layers, and embankments for design purposes.

The results of this study proved that the ratio CBR to DCP had very good linear relationship with the soil initial state factor, $F_{i}$. Based on this relationship, a reliable strong correlation has been established between the ratio CBR to
DCP and soil initial state factor. Comparison between the measured CBR/DCP values and the calculated results using the developed equation clearly indicated the reliability of this equation. Therefore, the DCP can be used to estimate the in-situ CBR value for the different pavement layers.

\section{REFERENCES}

[1] AASHTO: Standard Specifications for Transportation Materials and Methods of Sampling and Testing, Part II Methods of Sampling and Testing. $25^{\text {th }}$ Edition. American Association of State Highway and Transportation Officials, Washington 2005.

[2] BSI: Methods of Test for Soils for Civil Engineering Purposes, Part 2 (BS 1377-2). British Standards Institution, London, 1990.

[3] A. J. Scala, "Simple method of flexible pavement design using cone penetrometers," in Proc. $2^{\text {nd }}$ Australian - New Zealand Conference on Soil Mechanics and Foundation Engineering, vol. 11, no. 12, New Zealand, 1956.

[4] J. A. Harison, "Correlation between California bearing ratio and dynamic cone penetrometer strength measurement of soils," in Proc Institution of Civil Engineers, pp. 833-844, 1987.

[5] P. K. Sahoo and K. S. Reddy: "Evaluation of subgrade soils using dynamic cone penetrometer," International Journal of Earth Sciences and Engineering, ISSN 0974-5904, vol. 2, no. 4, pp. 384-388, 2009.

[6] M. Livneh, "Validation of correlations between a number of penetration tests and in-situ California bearing ratio tests," TRRL, pp. 56-57, 1989

[7] E. G. Kleyn, "The use of the dynamic cone penetrometer (DCP)," report 2/74. transvaal roads department," Rehabilitated Pavement Structures, Final Document, p.19,1975.

[8] R. B. Smith and D. N. Pratt: "A field study of in Situ California bearing ratio and dynamic cone penetrometer testing for road subgrade investigation," Australian Road Research, vol. 13, no. 4, pp. 285-293, 1983.

[9] M. Livneh and I. Ishai, "Pavement and material evaluation by a dynamic cone penetrometer," in Proc. Sixth International Conference on the Structural Design of Asphalt Pavement, vol. 1, Ann Arbor, Michigan, pp. 665-674, 1987.

[10] J. A. Harrison, "Correlation of CBR and dynamic cone penetrometer strength measurement of soils," Australian Road Research, vol 16, no. 2, pp. 130-136, 1986.

[11] S. L. Webster, R. H. Grau, and R. P. Williams, "Description and application of dual mass dynamic cone penetrometer," U.S. Army Engineer Waterways Experiment Station, Instruction Report, No. GL-92-3, 1992.

[12] D. H. Chen, J. N. Wang, and J. Bilyeu, "Application of the DCP in evaluation of base and subgrade layers," in Proc. 80th Annual Meeting of Transportation Research Board, Washington, D.C, January 2001.

[13] L. R. Sampson, "Investigation of the correlation between CBR and DCP," National Institute for Transport and Road Research, pp. 145-151, 1984.

[14] A. E. M. Mohamed, "Microstructure and swelling characteristics of an untreated and lime-treated compacted black cotton soil," $\mathrm{Ph}$. D thesis. University of Strathclyde, Glasgow, 1986.

[15] M. M. E. Zumrawi, "Performance and design of expansive soils as road subgrade," Ph.D. thesis, Chang'an Univ., China, 2000.

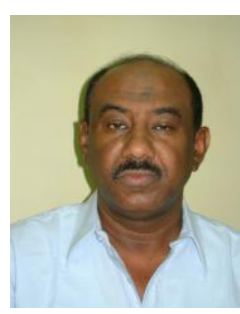

M. M. E. Zumrawi was born in Omdurman, Sudan, 19 May 1963. He achieved Ph.D. in highway and railway engineering, Chang'An University, Xi'an, China, 2000; M.Sc. in road technology, University of Khartoum, Sudan, 1992; B.Sc. in civil engineering, University of Khartoum, 1987.

His present occupation is the head of Soil \& Road Section, Civil Eng. Dept., Faculty of Eng., Khartoum University, since 2010.

$\mathrm{He}$ is working with local and international consultant firms. He has published articles in local and international journals and attended national and international conferences (CEBM 2012). He is a member of International Society for Soil Mechanics and Geotechnical Eng. (ISSMGE). 